\title{
Сакральные ландшафты и этнокультурные проекции коренных народов амуро-сахалинского региона
}

В процессе адаптации этноса к окружающей природно-социальной среде возникают условия для построения этнической картины мира, которая нередко возникает как бессознательный и специфичный для конкретной культуры феномен. В окрестностях современных поселений тунгусо-маньчжуров и палеоазиатов (нанайцев, негидальцев, нивхов, орочей, удэгейцев, уйльта, ульчей, эвенков) на территории амуро-сахалинского региона расположены природные и рукотворные объекты, генезис которых связан с двумя основными ментальными вариантами. Один - с образами сверхъестественных существ, с мифическими предками, основателями конкретных родовых подразделений. Другой - с потенциально реальными предками, которые проживали на этом месте еще в каменном веке и оставили о себе память в виде разнообразных петроглифов.

Осознание наличия данных фрактов вызывает у коренных народов гордость, историческую память и особую этнокультурную идентичность. Сравнительный анализ степени влияния сакральных ландшафтов и связанных с ними разнообразных этнографических данных на современную культуру тунгусо-маньчжуров и палеоазиатов позволит выявить специфику развития и трансформации этнокультурной идентичности. Важным компонентом этого контекста является выяснение сущности феноменов "этнокультурная проекция" (которая понимается как сложный процесс перенесения свойств внешнего объекта, в данном случае образа сакральных ландшафртов, на менталитет людей), и "интроекция", как специфического механизма встраиваемости окружающего мира во внутренний мир человека. Сакральные ландшафты, музеи под открытым небом, другие этнокультурные институты выступают средоточием коллективной исторической памяти этноса, первоисточниками знаний о развитии общества.

В результате этнокультурного проецирования происходит перенесение человеком на самого себя качеств окружающего мира. Взаимосвязь этнокультурной проекции с этнической идентичностью позволяет индивиду концентрировать в себе исторические знания о развитии своего этноса, о влиянии на этот процесс природных условий, климата, ландшафта. Механизм этнокультурной проекции во многом основан на сравнении своего этноса с другими, на представлении своего сообщества в наиболее блалгоприятном свете, что связано с древностью происхождения, численностью, размером занимаемой территории, этнокультурными связями и традициями.

Этнокультурная проекция проявляется в определенной этнической среде через механизм подражания не только старшему поколению, но и далёким предкам, нередко легендарным. Индивид копирует стереотипы поведения этнической общности как доминирующие ценности. Определённое влияние на этот процесс оказывают конкретные исторические предпосылки, общественные потребности осознания родства или идентичности для сплачивания этнической общности. Дополнительной детерминантой является этнокондес-

\section{(C) Березницкий C. В., 2021}

Березницкий Сергей Васильевич, д-р ист. наук, ведущий научный сотрудник отдела этнографии Сибири Музея антропологии и этнографии имени Петра Великого (Кунсткамера) РАН (2. Санкт-Петербург). E-mail: svbereznitsky@eandex.ru

Публикация подготовлена при фринансовой поддержке Программы фрундаментальных и прикладных научных исследований по теме "Этнокультурное многообразие российского общества и укрепление общероссийской идентичности" 2020-2022 гг. проект "Коренные малочисленные народы Российской Федерации" (рук. А.В. Головнёв). 
сиональный объединяющий фрактор, особенно если он связан с сакральными природными объектами, с особо почитаемыми частями ландшафрта. Ландшафно-этническая идентичность позволяет человеку проецировать на себя качества представителя конкретной местности, для которой характерны свой специфический диалект языка, свои нравы, обычаи, менталитет, этническая картина мира, мифология.

О сущности и структурных компонентах понятия "сакральный ландшафт", о соотношении их с особенностями этнических культур имеется обширная историографическая база, представленная трудами отечественных и зарубежных исследователей $[19 ; 3$, с. $13-36 ; 10$, с. $85-87 ; 11 ; 12$, с. 154-162; 4 , c. $27-31 ; 2016$, c. $76-78 ; 6$, c. $514-516 ; 16$, c. $161-177 ; 5$, c. $145-155 ; 14$, c. $106-121 ; 21$, c. $120-126]$.

Разрабатывая соотношение категорий "сакральное" и "профранное", М. Элиаде ввел в научный оборот термин "иерофания", которым обозначил сакральную, центральную часть окружающего человека профранного мира [30, c. 9; 29, с. 26]. Своеобразным продолжением концепции М. Элиаде становится парадигма иеротопии, как процесса создания сакральных ландшафтов, в качестве воспроизводства первоначального, мифологического сакрального пространства [15, с. 6-7]. По мысли Лидова, иеротопия включает в себя священные изображения, разнообразные архитектурные формы, обрядовые жесты, ольфакторные компоненты, аспекты исторической памяти, связь этноса с конкретным священным местом и с происходившими здесь событиями: профранными или сакральными.

Е.А.Окладникова рассмотрела френомен сакрального ландшафта Северной Евразии в качестве особой части ойкумены, которая была сформирована одновременно как реальное географическое и как воображаемое, мифологическое пространство с помощью создания петроглифов, различных ритуальных сооружений [20, с. 5, 22-29 и др.].

Важными компонентами ментального осмысления соотношения сакральных ландшафртов и этнокультурных проекций следует считать этническую картину мира, воззрения об объектах окружающего мира, аспекты топонимики и ее связь с институтом государственности.

Одним из фондаментальных отличий культуры коренных народов Дальнего Востока России от соседних стран Восточной Азии (Поднебесная империя, Страна утренней свежести, Страна восходящего солнца) является отсутствие подобного обобщающего названия для всей территории амуро-сахалинского региона, материковой части, побережий Охотского, Берингово или Чукотского морей. Средневековые империи, государства бохайцев и чжурчжэней активно контактировали с восточными цивилизациями (Китаем, Монголией, Кореей, Японией), о чем свидетельствуют сохранившиеся знания о былой торговле, отдельные инокультурные предметы быта и мировоззрения, мифологические сюжеты и разнообразные заимствованные жанры фольклора. В этнографическое время коренные народы Нижнего Амура участвовали в этнокультурных контактах с маньчжурами и китайцами, покупали невест в Маньчжурии и Китае [23, с. 64-75].

В традиционной культуре коренных народов региона одним из важных этноидентифицирующих факторов являлось занятие собаководством. В средневековых маньчжурских и китайских хрониках Приамурье называлось "страной собаководов", а населяющие эту территорию народы именовались термином "шицюаньбу" - "люди, пользующиеся собаками" [9, с. 98; 8; 22, с. $67 ; 26$, с. 6 ; 27, с. 7]. У некоторых групп эвенков, пеших охотников с собакой имелось самоназвание "хундышал" - "хозяева собак" [2, с. 10, 13].

Еще один устойчивый этнокультурный маркер связан с этнонимами "гиляк, гилэкэ, гилями, гилыми" ("люди, передвигающиеся при помощи парных весел на больших лодках"), с рекой Амур как важной круглогодичной транспортной магистралью, с лодкой амурского типа [28, с. 4]. На скалах в районе Нижнего Амура обнаружены почитаемые сегодня петроглифы каменного века, изображающие такие лодки, с гребцами и веслами.

Коренными народами дано большинство географических названий, которые потом перешли на карты, вошли в официальные названия населенных пунктов и в менталитет переселенцев. В частности, этимология названия "Сихотэ-Алинь" связана с тунгусо-маньчжурскими терминами: "сихтә, сик- 
тэ" - "хвоя, ель" и "алин" - "горный хребет", в целом, "горный хребет, покрытый хвойным лесом".

Можно выделить некоторые наиболее известные особые ландшафты с петроглифами, которые стали основой для этнокультурных проекций коренных народов региона, для исторической памяти, мифологических наслоений, в качестве связующей нити между людьми каменного века и современными тунгусо-маньчжурами и палеоазиатами.

В старинном нанайском селе Сикачи-Алян создан этнокультурный центр, где туристы могут увидеть собственными глазами знаменитые петроглифы каменного века, воплотившие в символическом виде мифологию амурских жителей [12, с. 154-162; 13, с. 244-255].

Во второй половине 1960-х гт. археологи под руководством А.П. Окладникова тщательно исследовали неолитические петроглифы на правом берегу р. Кии, притока Уссури, в местности Чертово Плесо. Сюжеты, наполнены криволинейным орнаментом, антропоморфными личинами, фоигурами духов-предков, животных и др. [19].

Проживающие в этих местах коренные народы твердо убеждены в том, что данные изображения на скалах и отдельных валунах сделали их прямые предки. Эта мысль приводит их к пониманию чрезвычайной древности своего этноса, к осознанию прав на уникальное пользование природными ландшафртами на этих территориях. Имеется и большой объем мифологических текстов, содержащих в себе информацию о далёких временах, когда на небе было несколько солнц, от тепла лучей которых становились мягкими скалы и охотники рисовали на них различные сюжеты. Миф продолжается тем, что герой по просьбе людей убивает стрелами из лука лишние светила. В нивхском варианте этого мифа этот герой летает верхом на крылатом олене, создает горы и реки $[7$, с. $81,83,89-90 ; 18$, с. $38-47 ; 17$, с. $13 ; 31$, с. 106-107; 24, c. 66-67; 25, с. 8-17]. Возможно, этот сюжет попал в культуру нивхов от тунгусо-маньчжуров.

Петроглифы на реке Хор некоторыми специалистами по искусству, отождествляются с современным искусством нанайцев, ульчей и других народов амуро-сахалинского региона. Сами хорские удэгейцы не просто считают, а настаивают на том, что они произошли от неолитического населения рек Хор и Сукпай, представители которого оставили эти рисунки на скалах около 2000 лет назад. Более того, выявляется даже родовая принадлежность этого священного этнокультурного памятника древности. По мнению местных удэгейцев, петроглифы могут быть связаны с современным удэгейским родовым подразделением Кимонко [32, р. 121].

Таким образом, рассмотренные в статье этнокультурные комплексы, священные ландшафты, природные и рукотворные объекты представляют в комплексе региональное сакральное пространство древности, средневековья и новейшего времени.

Священный антропогеокультурный ландшафрт - это френомен, созданный совместными усилиями природных стихий и франтазии человека. Этнокультурные проекции, возникшие в результате мировоззренческого осмысления священных ландшафртов, необходимы современным тунгусо-маньчжурам и палеоазиатам амуро-сахалинского региона для укрепления самосознания и этнокультурной идентичности, для улучшения процесса трансляции своих традиций новым поколениям.

Не менее важным компонентом соотношения взаимосвязи сакральных ландшафтов с этнокультурными проекциями является создание эфрфективной реакции в качестве ответа на современные глобальные вызовы, на изменения демографической ситуации в отдельных регионах и в стране, на стремительное появление в России и в её дальневосточном регионе компактно проживающих этнических сообществ, приносящих с собой не только другой уклад жизни, но и прочно сохраняющиеся этнокультурные аспекты, кардинально отличающиеся от традиционных российских ценностей. 


\section{Литература}

1. Алексеева Е.К. Этнокультурный ландшафт ламунхинских эвенов // Успехи современной науки и образования. 2016. № 11. Т. 8. С. 76-78. $303 \mathrm{c}$.

2. Василевич Г. М. Эвенки. Историко-этнографические очерки. Л.: Наука, 1969.

3. Веденин Ю.А., Кулешова М.Е. Культурные ландшафты как категория наследия // Культурные ландшафоты как объект наследия / под ред. Ю.А. Веденина, М.Е. Кулешовой. М.: Институт наследия; СПб.: Дмитрий Буланин, 2004. С. 13-36.

4. Воловик В.Н. Категории сакрального ландшафта // Географический вестник. 2013. № 4 (27). C. $26-34$.

5. Головнёва Е.В., Шанта И. Визуализация сакрального в культовой скульптуре народов Приамурья (по материалам коллекций В. К. Арсеньева и Б. Баратоши) // Известия Уральского федерального университета. Серия 1: проблемы образования, науки и культуры. 2019. Т. 25. № 3. С. 145-155.

6. Дэвлет Е. Г., Ласкин Е. Г. Исследования петроглифов Сикачи-Аляна // Археологические открытия. 2019. Т. 2017. С. 514-516.

7. Крейнович Е.А. Очерк космогонических представлений гиляк о-ва Сахалина // Этнография. Кн. VII. 1929. № 1. С. 78-102.

8. Кюнер Н. В. Китайские известия о народах Южной Сибири, Центральной Азии и Дальнего Востока. М.: Наука, 1961. 322 с.

9. Кюнер Н. В. Китайские исторические данные о народах Севера // Ученые Записки ЛГУ. Серия Востоковедческих наук. 1949. Вып. 1. № 98. С. 92-102.

10. Лапшина 3.С. Сакральное в первобытной культуре Приамурья // Россия и ATP. 2005. № 3. C. 84-88.

11. Ласкин А.Р. Петроглифы Сикачи-Аляна: Историко-культурный контекст и состояние сохранности. Автореферат на соиск. уч. ст. к.и.н. по спец. 07.00.06. М., 2015. $25 \mathrm{c}$.

12. Ласкин А.Р., Дэвлет Е.Г., Бабаев А.Л., Судаков А.И. Петроглифы Сикачи-Аляна - уникальный памятник древнего наскального искусства на Нижнем Амуре (проблемы сохранения и использования) // Мир наскального искусства / отв. ред. Е.Г. Дэвлет. М., 2005. С. 154-162.

13. Ласкин А.Р., Дэвлет Е.Г., Гринько А.Е., Свойский Ю.М., Романенко Е.В. Новые результаты документирования петроглифов и моделирования сакральных ландшафтов памятников наскального искусства Дальнего Востока // Проблемы истории, филологии, культуры. 2018. № 2. С. 244-255.

14. Латушко Ю. В., Самар А. П., Белая Е. Г., Левченко А. В. Историко-культурные ландшафры Амура в современной нанайской культуре (по материалам полевого исследования 2019 г.) // Ойкумена. Регионоведческие исследования. 2019. № 4. С. $106-121$.

15. Лидов А.М. Иеротопия. Пространственные иконы и образцы парадигмы в византийской культуре. М.: Дизайн. Информация. Картография, 2009. 362 с.

16. Мальцева О.В. Нанайцы в промышленном районе Приамурья: модель освоения пространства и поиск идентичности // Этнографическое обозрение. 2018. № 1. С. $161-177$.

17. Никитина М.И. Древняя корейская поэзия в связи с ритуалом и мифом. М.: Наука, 1982. $327 \mathrm{c.}$

18. Окладников А.П. Древние амурские петроглифы и современная орнаментика народов Приамурья // Советская этнографрия. 1959. № 2. С. 38-47.

19. Окладников А.П. Петроглифы Нижнего Амура. Л.: Наука. 1971. 335 с.

20. Окладникова Е.А. Сакральный ландшафрт: теория и эмпирические исследования. М.-Берлин: Директ-Медиа, 2014. 230 с.

21. Подмаскин В.В. Древние представления о тигре и леопарде у коренных народов Нижнего Амура и Сахалина как историко-этнографический источник // Манускрипт. 2020. Т. 13. Вып. 12. С. 120-126.

22. Самар А. П. Собаководство нанайцев в XIX - начале XX века // Этнос и природная среда / сб. ст. / отв. ред. В. А. Тураев. Владивосток: Дальнаука. 1997. С. 67-81.

23. Сасаки С. Межэтнические браки коренных народов Нижнего Амура и Сахалина // Россия и АТР. 2008. № 2. С. 64-75.

24. Сем Т.Ю. Амурский солярный миф: генезис и этнокультурные связи // Лингвистические вопросы североведения. Тезисы докладов и сообщений Герценовских чтений 1993/1994 г. СПб.: "Образование", 1997. С. 66-67.

25. Сем Т.Ю., Окладникова Е.А. "Миф о трех солнцах": семантика и визуальная репрезентация в монументальном искусстве Древней Евразии // Северо-Восточный гуманитарный вестник. 2021. № 1. С. 8-17.

26. Сем Ю. А. Родовая организация нанайцев и её разложение. Владивосток, 1959. $31 \mathrm{c}$.

27. Сем Ю. А. Нанайцы: материальная культура (вторая половина ХІХ - середина XX в.). Этнографические очерки. Владивосток: ДВНЦ АН СССР, 1973. 315 с. 
28. Таксами Ч. М. Основные проблемы этнографии и истории нивхов (середина XIX - начало XX в.). Л.: Наука, 1975. 235 с.

29. Элиаде М. Избранные сочинения: Миф о вечном возвращении; Образы и символы; Священное и мирское. М.: Ладомир, 2000. 488 с.

30. Элиаде М. Священное и мирское. М.: Издательство МГУ, 1994. 144 с.

31. Яншина Э.М. Формирование и развитие древнекитайской мифологии. М.: Наука, 1984. 246 с.

32. Bereznitsky S.V. Forest problems in today's culture of the Khor Udeghe // Russia County Report. IGES Forest Conservation Project / Japan, Yokohama: Published by Institute for Global Environmental Strategies / ed. By. H. Kakizawa. January 2004. P. $120-134$.

\section{Транслитерация по ГОСТ 7.79-2000 Система Б}

1. Alekseeva E.K. EHtnokul'turnyj landshaft lamunkhinskikh ehvenov // Uspekhi sovremennoj nauki i obrazovaniya. 2016. № 11. T. 8. S. 76-78.

2. Vasilevich G. M. EHvenki. Istoriko-ehtnograficheskie ocherki. L.: Nauka, 1969. $303 \mathrm{~s}$.

3. Vedenin YU.A., Kuleshova M.E. Kul'turnye landshafty kak kategoriya naslediya // Kul'turnye landshafty kak ob"ekt naslediya / pod red. YU.A. Vedenina, M.E. Kuleshovoj. M.: Institut naslediya; SPb.: Dmitrij Bulanin, 2004. S. 13-36.

4. Volovik V.N. Kategorii sakral'nogo landshafta // Geograficheskij vestnik. 2013. № 4 (27). S. $26-34$.

5. Golovnyova E.V., SHanta I. Vizualizatsiya sakral'nogo v kul'tovoj skul'pture narodov Priamur'ya (po materialam kollektsij V. K. Arsen'eva i B. Baratoshi) // Izvestiya Ural'skogo federal'nogo universiteta. Seriya 1: problemy obrazovaniya, nauki i kul'tury. 2019. T. 25. № 3. S. 145-155.

6. Dehvlet E. G., Laskin E. G. Issledovaniya petroglifov Sikachi-Alyana // Arkheologicheskie otkrytiya. 2019. T. 2017. S. 514-516.

7. Krejnovich E.A. Ocherk kosmogonicheskikh predstavlenij gilyak o-va Sakhalina // EHtnografiya. Kn. VII. 1929. № 1. S. 78-102.

8. Kyuner N. V. Kitajskie izvestiya o narodakh YUzhnoj Sibiri, TSentral'noj Azii i Dal'nego Vostoka. M.: Nauka, 1961. 322 s.

9. Kyuner N. V. Kitajskie istoricheskie dannye o narodakh Severa // Uchenye Zapiski LGU. Seriya Vostokovedcheskikh nauk. 1949. Vyp. 1. № 98. S. 92-102.

10. Lapshina Z.S. Sakral'noe v pervobytnoj kul'ture Priamur'ya // Rossiya i ATR. 2005. № 3. S. 84-88.

11. Laskin A.R. Petroglify Sikachi-Alyana: Istoriko-kul'turnyj kontekst i sostoyanie sokhrannosti. Avtoreferat na soisk. uch. st. k.i.n. po spets. 07.00.06. M., 2015. 25 s.

12. Laskin A.R., Dehvlet E.G., Babaev A.L., Sudakov A.I. Petroglify Sikachi-Alyana - unikal'nyj pamyatnik drevnego naskal'nogo iskusstva na Nizhnem Amure (problemy sokhraneniya i ispol'zovaniya) // Mir naskal'nogo iskusstva / otv. red. E.G. Dehvlet. M., 2005. S. 154-162

13. Laskin A.R., Dehvlet E.G., Grin'ko A.E., Svojskij YU.M., Romanenko E.V. Novye rezul'taty dokumentirovaniya petroglifov i modelirovaniya sakral'nykh landshaftov pamyatnikov naskal'nogo iskusstva Dal'nego Vostoka // Problemy istorii, filologii, kul'tury. 2018. № 2. S. 244-255.

14. Latushko YU. V., Samar A. P., Belaya E. G., Levchenko A. V. Istoriko-kul'turnye landshafty Amura v sovremennoj nanajskoj kul'ture (po materialam polevogo issledovaniya 2019 g.) // Ojkumena. Regionovedcheskie issledovaniya. 2019. № 4. S. 106-121.

15. Lidov A.M. Ierotopiya. Prostranstvennye ikony i obraztsy paradigmy v vizantijskoj kul'ture. M.: Dizajn. Informatsiya. Kartografiya, 2009. 362 s.

16. Mal'tseva O.V. Nanajtsy v promyshlennom rajone Priamur'ya: model' osvoeniya prostranstva i poisk identichnosti // EHtnograficheskoe obozrenie. 2018. № 1. S. 161-177.

17. Nikitina M.I. Drevnyaya korejskaya poehziya v svyazi s ritualom i mifom. M.: Nauka, 1982. $327 \mathrm{~s}$.

18. Okladnikov A.P. Drevnie amurskie petroglify i sovremennaya ornamentika narodov Priamur'ya // Sovetskaya ehtnografiya. 1959. № 2. S. 38-47.

19. Okladnikov A.P. Petroglify Nizhnego Amura. L.: Nauka. 1971. 335 s.

20. Okladnikova E.A. Sakral'nyj landshaft: teoriya i ehmpiricheskie issledovaniya. M.-Berlin: Direkt-Media, 2014. $230 \mathrm{~s}$.

21. Podmaskin V.V. Drevnie predstavleniya o tigre i leoparde u korennykh narodov Nizhnego Amura i Sakhalina kak istoriko-ehtnograficheskij istochnik // Manuskript. 2020. T. 13. Vyp. 12. S. $120-126$.

22. Samar A. P. Sobakovodstvo nanajtsev v XIX - nachale XX veka // EHtnos i prirodnaya sreda / sb. st. / otv. red. V. A. Turaev. Vladivostok: Dal'nauka. 1997. S. 67-81.

23. Sasaki S. Mezhehtnicheskie braki korennykh narodov Nizhnego Amura i Sakhalina // Rossiya i ATR. 2008. № 2. S. 64-75. 
24. Sem T.YU. Amurskij solyarnyj mif: genezis i ehtnokul'turnye svyazi // Lingvisticheskie voprosy severovedeniya. Tezisy dokladov i soobshhenij Gertsenovskikh chtenij 1993/1994 g. SPb.: "Obrazovanie", 1997. S. 66-67.

25. Sem T.YU., Okladnikova E.A. "Mif o trekh solntsakh": semantika i vizual'naya reprezentatsiya v monumental'nom iskusstve Drevnej Evrazii // Severo-Vostochnyj gumanitarnyj vestnik. 2021. № 1 . S. 8-17.

26. Sem YU. A. Rodovaya organizatsiya nanajtsev i eyo razlozhenie. Vladivostok, 1959. $31 \mathrm{~s}$.

27. Sem YU. A. Nanajtsy: material'naya kul'tura (vtoraya polovina XIX- seredina XX v.). EHtnograficheskie ocherki. Vladivostok: DVNTS AN SSSR, 1973. 315 s.

28. Taksami CH. M. Osnovnye problemy ehtnografii i istorii nivkhov (seredina XIX - nachalo XX v.). L.: Nauka, 1975. 235 s.

29. EHliade M. Izbrannye sochineniya: Mif o vechnom vozvrashhenii; Obrazy i simvoly; Svyashhennoe i mirskoe. M.: Ladomir, 2000. $488 \mathrm{~s}$.

30. EHliade M. Svyashhennoe i mirskoe. M.: Izdatel'stvo MGU, 1994. 144 s.

31. YAnshina EH.M. Formirovanie i razvitie drevnekitajskoj mifologii. M.: Nauka, 1984. $246 \mathrm{~s}$.

32. Bereznitsky S.V. Forest problems in today's culture of the Khor Udeghe // Russia County Report. IGES Forest Conservation Project / Japan, Yokohama: Published by Institute for Global Environmental Strategies / ed. By. H. Kakizawa. January 2004. P. 120-134.

\section{Березницкий С. В. Сакральные ландшафты и этнокультурные проек- ции коренных народов амуро-сахалинского региона.}

Сакральные ландшафты коренных народов амуро-сахалинского региона (нанайцев, негидальцев, нивхов, орочей, удэгейцев, уйльта, ульчей, эвенков) оказывают ментальное влияние на процесс возникновения этнокультурных проекций. Феномен "этнокультурная проекция" понимается как механизм перенесения качеств внешнего объекта, явления на субъект. В данной статье под внешним объектом подразумеваются сакральные ландшафты, комплексы петроглифров, этнографические экспонаты, а роль субъекта играют представители указанных этносов. Этнокультурные проекции проявляются в контексте мифологического восприятия сакральных ландшадтов, воссоздания коллективной памяти в результате осмысления этнографических материалов, различных видов материального и нематериального культурного наследия.

Ключевые слова: Алуро-сахалинский регион, тунгусо-ланьчжурь $u$ палеоазиаты, сакральные ландшафбты, этнокультурные проекции

Bereznitsky S. V. Sacred landscapes and ethno-cultural projections of the indigenous peoples of the Amur-Sakhalin region.

The sacred landscapes of the indigenous peoples of the Amur-Sakhalin region (Nanais, Negidals, Nivkhis, Orochis, Udeges, Uiltas, Ulchis, Evenks) have a mental impact on the process of the emergence of ethno-cultural projections. The phenomenon of "ethno-cultural projection" is understood as a mechanism for transferring the qualities of an external object, phenomenon to the subject. In this article, the external object refers to sacred landscapes, petroglyph complexes, ethnographic exhibits, and the role of the subject is played by representatives of these ethnic groups. Ethno-cultural projections are manifested in the context of the mythological perception of sacred landscapes, the reconstruction of collective memory as a result of the comprehension of ethnographic materials, various types of tangible and intangible cultural heritage.

Key words: Amur-Sakhalin region, Tunguso-Manchus and Paleoasiates, sacred landscapes, ethno-cultural projections

Для цитирования: Березницкий С. В. Сакральные ландшафты и этнокультурные проекции коренных народов амуро-сахалинского региона // Ойкумена. Регионоведческие исследования. 2021. № 3. С. 24-29. DOI: 10.24866/1998-6785/2021-3/24-29

For citation: Bereznitsky S. V. Sacred landscapes and ethno-cultural projections of the indigenous peoples of the Amur-Sakhalin region // Ojkumena. Regional researches. 2021. № 3 . P. 24-29. DOI: $10.24866 / 1998-6785 / 2021-3 / 24-29$ 